\title{
Enfoque Sistémico de la gestión local del riesgo por inundación. El caso de la subcuenca del río Caldera en el Distrito de Boquete, Panamá
}

\author{
Catalina Elvira Espinosa Vega ${ }^{1,2}$ esvecaellabsig@gmail.com; Itzel Arriaga Hurtado ${ }^{3}$
}

\begin{abstract}
RESUMEN
Se analiza la gestión local del riesgo por inundación como un proceso social sistémico complejo, dentro del sistema social del Distrito de Boquete en Panamá. Dicho análisis se realiza desde la línea de investigación de la Geografía de los Riesgos como área de conocimiento de la Geografía Humana. A partir de esta área se considera la pertinencia de basar la estructura metodológica en un marco teórico a partir de la Teoría de los Sistemas Sociales de Luhmann (1998) y se realiza un análisis sintético de la gestión local de riesgo por inundación desde el cual se deduce y aporta la naturaleza geográfica de la misma. Estos planteamientos teóricos-conceptuales se confrontan con el caso de estudio: la subcuenca del río Caldera, ubicada en el distrito de Boquete, que es un área de multi-amenazas, donde la amenaza por inundación se determina como fenómeno a investigar. A partir de dicho análisis se resalta la participación ciudadana como uno de los subsistemas trascendentales que pueden asegurar la eficacia de la gestión local del riesgo por inundación. Por otra parte, estos planteamientos permitieron deducir y analizar las características y el funcionamiento de los subsistemas geográfico físico, geográfico humano, histórico, económico, político, cultural y jurídico que conforman el sistema social estudiado y que a partir de su falta de comunicación, la entropía y la irritabilidad entre ellos, determinan y condicionan el comportamiento de la gestión local del riesgo por inundación, siendo ello uno de los aportes científicos de este artículo.
\end{abstract}

Palabras clave: Sistema, gestión local del riesgo por inundación, Participación ciudadana.

\section{Systemic approach of local flood risk management. The case of the Caldera river sub-basin in the District of Boquete, Panamá}

\begin{abstract}
This study aims to analyze the local flood risk management as a complex systemic social process within the social system of the District of Boquete in Panama; this analysis is performed from the line research of the Geography of Risk as knowledge area of the Human Geography. From this area is considered the pertinence of basing the methodological structure on a theoretical framework as of the Theory of Social Systems according Luhmann (1998) and is performed a synthetic analysis of the local flood risk management from which it is deduce and provides the geographical nature of it. These theoretical-conceptual approaches are confronted with the case study: the sub-basin of the Caldera river, located in the district of Boquete, for being an area of multi-hazard, where flood hazard is determined as the phenomenon to investigate. From this analysis highlights the citizen participation as one of the momentous subsystems that can ensure the effectiveness of local flood risk management. On the other hand, these approaches allowed deduce and analyze the characteristics and functioning of the subsystems: physical geographical, human geographical, historic, economic, political, cultural, legal that comprise the social system studied and from its lack of communication, entropy and irritability among them, determine and condition the behavior of local flood risk management, this being the first scientific contribution of this paper.
\end{abstract}

Keywords: system, local flood risk management, citizen participation.

Recibido el 5 de mayo de 2014, aceptado el 18 de diciembre de 2014.

1 Universidad Autónoma de Chiriquí, Ciudad Universitaria-El Cabrero. David, Chiriquí, Estafeta Universitaria. Apartado 0427. Panamá, CP.

2 Universidad de Quintana Roo, México, CP.

3 Universidad Autónoma del Estado de México, México. 


\section{INTRODUCCIÓN}

En el Istmo Centroamericano, la gestión del riesgo de desastres surge como consecuencia del cambio de paradigma después de las pérdidas y daños que dejó el Huracán Mitch, en 1998. Fue así que surgieron nuevos planteamientos teóricosconceptuales, tanto de los investigadores que trabajaron sobre los riesgos y desastres previos al Mitch, como de las organizaciones gubernamentales y no gubernamentales nacionales e internacionales. En el ámbito local surgen análisis y reflexiones con respecto a cómo habían sido manejados el riesgo y los desastres en los países afectados, como Honduras, Nicaragua, El Salvador y Guatemala.

La gestión del riesgo de desastres se constituye como uno de los términos de uso frecuente en la reducción del riesgo de desastres. La gestión del riesgo de desastres es definida por la UNITED NATIONS OFFICE FOR DISASTER RISK REDUCTION (2009: 19) como "un proceso sistemático que utiliza directrices administrativas, organizaciones, destrezas y capacidades operativas para ejecutar políticas y fortalecer las capacidades de afrontamiento, con el fin de reducir el impacto adverso de las amenazas naturales y la posibilidad de que ocurra un desastre".

En consecuencia a lo anterior, uno de los planteamientos teóricos-conceptuales de la gestión del riesgo de desastres que surgen en la década de los 90, es la gestión local del riesgo de desastres. Cabe señalar que el grupo de científicos que sentó las bases teóricas sobre la gestión del riesgo de desastres en Latinoamérica, incluyendo la gestión local del riesgo de desastres, es la Red de Estudios Sociales en Prevención de Desastres en América Latina, creada en 1992 por un colectivo científico, interinstitucional y multidisciplinario de especialistas que promueven el enfoque social de los desastres y que han generado líneas de investigación que han fortalecido el manejo de los desastres en Latinoamérica. Es así que surgen planteamientos teóricos-conceptuales sobre la gestión local del riesgo. MASKREY (1989) la refiere como un modelo y sugiere descentralizar a escala local el manejo (gestión) de desastres e incorporar a todos los actores de la sociedad civil; considera fundamental la participación ciudadana para logar la eficacia en la prevención, manejo y reducción del riesgo. En tanto, WILCHESCHAUX (1998) señala la tendencia en el fortalecimiento de la gestión desde lo local, que en el caso de América Latina es la administración municipal. Para ARGÜELLO (2002: 6), la gestión local del riesgo va más allá de un planteamiento teórico y es evidente al expresar que ésta "implica una valoración de las inmensas inversiones públicas y de la cooperación internacional". BOLLÍN (2003) concibe la gestión local del riesgo como la participación de los actores locales en todas las fases del riesgo. Además de lo anterior, BOLLIN (2003) incluye en el modelo de la gestión local del riesgo, acciones de análisis del riesgo, de la gestión del riesgo y de la preparación ante el caso de emergencia. Este autor, al igual que WILCHEX-CHAUX (1998), concede un papel importante a la administración municipal en la gestión local del riesgo, y coincide con MASKREY (1989) en la descentralización de la gestión.

Posteriormente se ha continuado con el fortalecimiento del marco conceptual de la gestión local del riesgo de desastre y es así que LAVELL (2009) se refiere a la gestión local del riesgo como aquellos procesos de la comunidad desarrollados por actores y organizaciones locales o comunitarias. Además, ligada a esta concepción, GELLERT (2012) aborda la gestión local del riesgo desde dos perspectivas: el número de desastres a escala local y la importancia de la dimensión local por la vinculación a los planes de desarrollo local o comunitario. Cabe agregar que los autores citados coinciden que aunque la gestión local del riesgo se lleva a cabo en la escala local, implica la coordinación con las otras escalas, regional, nacional e internacional. A pesar de dichas 
síntesis conceptuales, hasta el año 2014 no existe una definición consensuada y de uso común sobre la gestión local del riesgo de desastres. La UNITED NATIONS OFFICE FOR DISASTER RISK REDUCTION (2009) no la define explícitamente.

En este marco conceptual, la presente investigación aborda la gestión local del riesgo por inundación desde la perspectiva de CALVO GARCÍA TORNEL (1984), quien señala que Geografía de los Riesgos ha permitido a los geógrafos incorporarse en las investigaciones sobre planificación, gestión y la ordenación de los espacios humanos que viven bajo la amenaza de afectación de un fenómeno natural. Esta línea de investigación es el puente entre el estudio de los fenómenos naturales, la geografía física de los lugares expuestos al riesgo, las poblaciones humanas, las estructuras sociales y las políticas públicas de gestión del riesgo de desastres. La línea de investigación Geografía de los Riesgos cuenta con varios enfoques, de los cuales se elige la Ecología Política. Este enfoque combina relaciones entre los miembros de una comunidad, las relaciones de esa comunidad con su entorno natural y las relaciones entre la sociedad civil y las instituciones políticas de esa comunidad (OLIVER-SMITH 2013). Para la Ecología Política se trata de relaciones de poder, procesos y conflictos que se suceden a escalas regional (región centroamericana), territorial (Panamá) y local (subcuenca del río Caldera). Tales relaciones de poder determinan la gestión local del riesgo (SUTTON \& ANDERSON 2010). Esta perspectiva permite la construcción de la naturaleza geográfica de la gestión local del riesgo, el fundamento como un proceso sistémico y la confrontación con el caso de estudio, que es la subcuenca del río Caldera.

El sistema social en el que se desarrolla la subcuenca del río Caldera se localiza en el distrito de Boquete, provincia de Chiriquí, al oeste de Panamá (Fig.1), es una zona que pertenece a las Tierra Altas, constituida por un relieve montañoso, con elevaciones superiores a 2000 m.s.n.m y pendientes abruptas. Según la clasificación climática de KÖPPEN-GEIGER, la subcuenca del río Caldera se caracteriza por un clima templado muy húmedo sin estación seca (Cf). Tiene una temperatura promedio de 20,5 $5^{\circ} \mathrm{C}$ (EMPRESA DE TRANSMISIÓN ELÉCTRICA 2014). La precipitación es elevada, sobre todo en los meses de la época lluviosa (mayo a noviembre), con una media anual de $3.466 \mathrm{~mm}$. al año (ROGELIS et al. 2014) y una escorrentía de $2.433 \mathrm{~mm}$. al año (VAN DE WEERT 2009). La subcuenca del río Caldera se enclava en un distrito con una población de 21.370 habitantes (INSTITUTO NACIONAL DE ESTADÍSTICA Y CENSO DE LA REPÚBLICA DE PANAMÁ 2010). El río Caldera atraviesa las comunidades de Bajo Boquete, que es la cabecera del distrito, y Los Naranjos, uno de los corregimientos más poblados de los seis existentes. $\mathrm{La}$ mayor parte de la población se dedica a las actividades agrícolas y turísticas, por las características topográficas y climáticas.

Las principales amenazas de la subcuenca del río Caldera en el sistema social del distrito de Boquete tienen como factores causales que las condicionan tanto los fenómenos geológicos como hidrometeorológicos. En consecuencia, se han escenificado deslizamientos, sismos e inundaciones. Estas últimas, por su frecuencia, intensidad y duración, son las que han causado más pérdidas de vida humana y materiales (Tabla 1). Lo anterior establece la relevancia de este estudio que contribuye a la construcción del fenómeno de gestión local del riesgo por inundación y al análisis sistémico de esta, así como la observación sistémica de los factores causales y consecuenciales que se desarrollan en la subcuenca del río Caldera y por tanto puede contribuir a crear estrategias de reducción del riesgo por inundación a través de la gestión local del riesgo, incluyendo a la participación ciudadana como subsistema integral y determinante para su eficacia. 


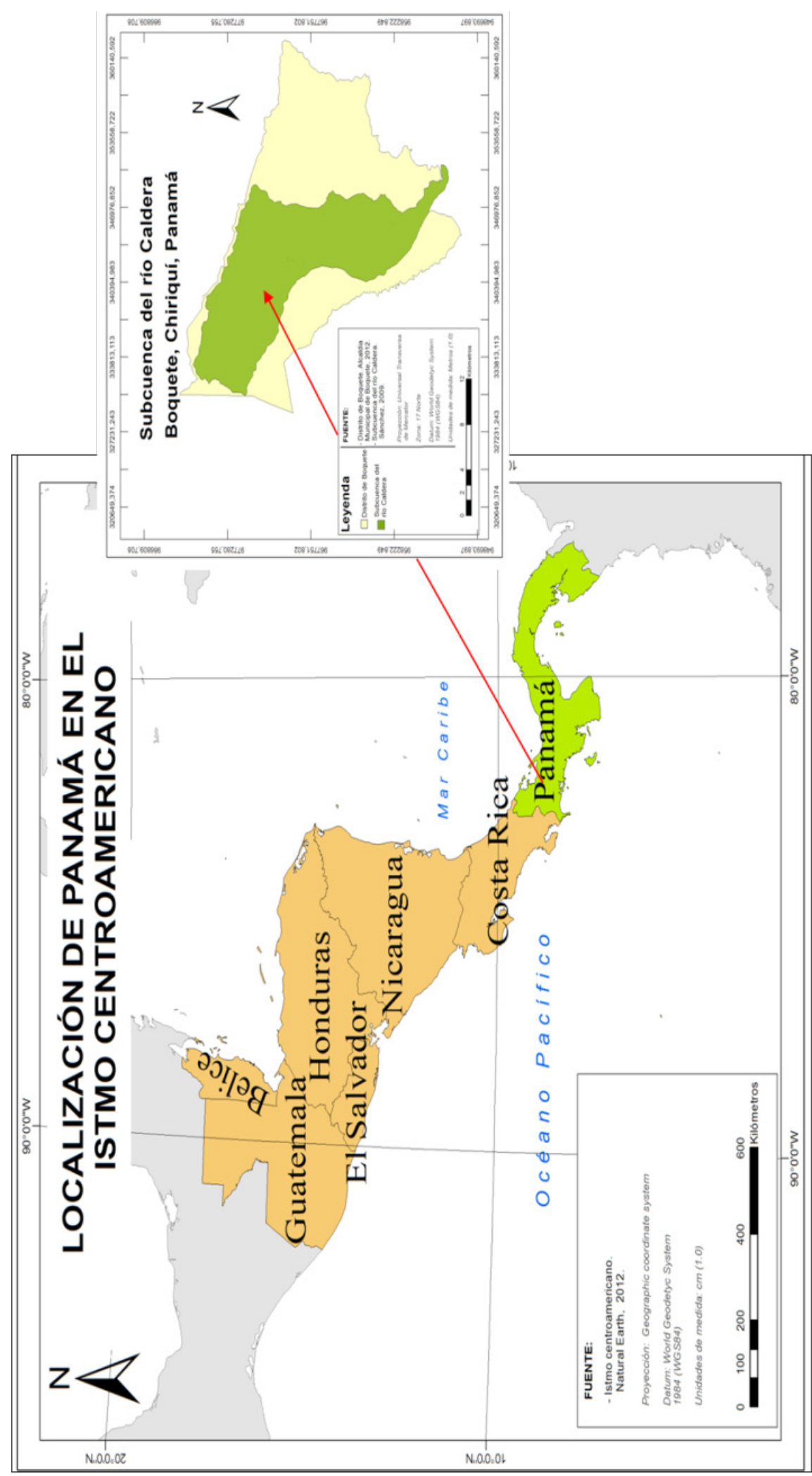

苞 
Tabla 1. Principales inundaciones en la subcuenca del río Caldera, Panamá. 1938-2011.

Table 1. Major flooding in the sub basin of the Caldera River, Panamá. 1938-2011.

\begin{tabular}{|c|c|c|c|}
\hline Año & Mes/Día & Descripción & Afectación \\
\hline 1938 & $\begin{array}{l}\text { No } \\
\text { definido }\end{array}$ & Daños en Palmira, Boquete y Jaramillo. & Catalogada como alta \\
\hline 1969 & Agosto 12 & $\begin{array}{l}\text { Desbordamiento de la quebrada Horqueta, } \\
\text { causada por lluvias. }\end{array}$ & $\begin{array}{c}\text { Arrastre de fincas y una vivienda. Además, } 4 \\
\text { muertos y daños en miles de balboas (\$). }\end{array}$ \\
\hline 1970 & $\begin{array}{c}\text { Enero } \\
\text { No definido }\end{array}$ & Desbordamiento del río Caldera. & $\begin{array}{c}\text { Arrastre de fincas y algunas residencias a } \\
\text { orillas del río Caldera. }\end{array}$ \\
\hline 1970 & Abril 6 & $\begin{array}{l}\text { Causada por una convergencia desde el } \\
\text { oeste de Cartagena, Colombia, avanzando } \\
\text { hacia la dirección Este de Panamá y a su } \\
\text { vez una masa de aire frío y seco desde el } \\
\text { suroeste hacia el Este sobre Costa Rica } \\
\text { y occidente de Panamá. Se registró una } \\
\text { precipitación de } 367 \text { mm en } 24 \text { horas. }\end{array}$ & Sector alto y medio de la cuenca. \\
\hline 1970 & $\begin{array}{c}\text { Abril } \\
9-10-11\end{array}$ & $\begin{array}{l}\text { Se registran lluvias torrenciales por } 3 \text { días } \\
\text { y el cauce del río Caldera aumenta hasta } \\
3 \text { metros de altura, causando un desli- } \\
\text { zamiento de tierra en la cabecera de la } \\
\text { cuenca, provocando embalses y el cambio } \\
\text { del curso hacia el borde oriental del valle. }\end{array}$ & $\begin{array}{l}\text { Arrastre de } 120 \text { casas a orillas del río. Colap- } \\
\text { so de puentes. Dos personas desaparecidas y } \\
500 \text { damnificados. Varios millones de balboas } \\
\text { en pérdidas. Destrucción de una tercera parte } \\
\text { del distrito. Provocó la migración a otros } \\
\text { lugares de la provincia y la creación de nú- } \\
\text { cleos de población en el actual corregimiento } \\
\text { de Alto Boquete. }\end{array}$ \\
\hline 1990 & $\begin{array}{c}\text { Noviembre } \\
4-5\end{array}$ & $\begin{array}{l}\text { Se registró una alta precipitación en } 48 \\
\text { horas en las estaciones de Los Naranjos de } \\
205.4 \mathrm{~mm} \text { y en Finca Lérida de } 98.9 \mathrm{~mm} \text {, } \\
\text { causando el desbordamiento de las quebra- } \\
\text { das Callejón Seco, Aserrío y Grande. }\end{array}$ & $\begin{array}{l}\text { Pérdida de una vida humana. Daños en } \\
\text { infraestructuras, caminos, cultivos de café, } \\
\text { viviendas. Los daños ascendieron a más de } \\
200.000 \text { balboas (\$). }\end{array}$ \\
\hline 1991 & $\begin{array}{l}\text { Octubre } \\
9-10-11-12\end{array}$ & $\begin{array}{l}\text { Causada por precipitaciones en la falda } \\
\text { del Volcán Barú (Camiseta, El Trompo, } \\
\text { El Salto y Callejón Seco). En } 4 \text { días se } \\
\text { registraron } 269 \mathrm{~mm} \text {. El día } 11 \text { se registró } \\
\text { el } 65 \% \text { del total. En una hora (4:00 a 5:00 } \\
\text { p.m.) se registraron } 83 \mathrm{~mm} .\end{array}$ & $\begin{array}{l}\text { Pérdida por varios miles de balboas. Afec- } \\
\text { tación de fincas de café y las carreteras de } \\
\text { acceso a las mismas. No hubo pérdidas } \\
\text { humanas. }\end{array}$ \\
\hline 1995 & $\begin{array}{l}\text { Junio } \\
19-20\end{array}$ & $\begin{array}{l}\text { Se registran lluvias torrenciales después } \\
\text { del mediodía hasta altas horas de la noche, } \\
\text { causando derrumbes e inundaciones en } \\
\text { el área de Boquete, Jaramillo Centro, El } \\
\text { Salto. Se desbordó la quebrada Aserrío, } \\
\text { causando un flujo de detritos en la Coope- } \\
\text { rativa Hortícola y de Mercadeo. }\end{array}$ & $\begin{array}{l}\text { Evacuación de } 500 \text { personas. Pérdida de una } \\
\text { vida. La carretera que conduce a los Naranjos } \\
\text { quedó interrumpida. } \\
\text { Las pérdidas de infraestructuras y cultivos se } \\
\text { estiman en más de un millón de balboas. }\end{array}$ \\
\hline
\end{tabular}




\begin{tabular}{|c|c|c|c|}
\hline 2005 & $\begin{array}{l}\text { Enero } \\
\quad 9\end{array}$ & $\begin{array}{l}\text { Causada por una abundante precipitación } \\
\text { orográfica o bajareque, lo que provocó el } \\
\text { desbordamiento del río Caldera y varios } \\
\text { deslizamientos en la subcuenca. }\end{array}$ & $\begin{array}{l}\text { La comunidad de Bajo Mono fue la más } \\
\text { afectada en sus vías de comunicación ( } 100 \\
\text { metros) y el puente que conduce al sector de } \\
\text { Arco Iris. Hubo daños en cultivos agrícolas } \\
\text { y afectaciones en la entrada al sendero Los } \\
\text { Quetzales. Las pérdidas se calculan en un } \\
\text { millón de balboas. La Feria de las Flores y el } \\
\text { Café cerró por } 3 \text { días. }\end{array}$ \\
\hline 2008 & $\begin{array}{l}\text { Noviembre } \\
22\end{array}$ & $\begin{array}{c}\text { Se registró un frente frío y un sistema de } \\
\text { baja presión, causando el desbordamiento } \\
\text { del río Caldera. }\end{array}$ & $\begin{array}{l}\text { Daños en el } 50 \% \text { de los terrenos de la Feria de } \\
\text { las Flores y el Café, con pérdidas de } 250 \text { mil } \\
\text { balboas invertidas. Además, daños en los ho- } \\
\text { teles Ladera, Palo Alto Riverside y Rebequet. } \\
\text { Varios poblados quedaron incomunicados. }\end{array}$ \\
\hline 2010 & $\begin{array}{l}\text { Agosto } \\
22\end{array}$ & $\begin{array}{c}\text { Desbordamientos del río Caldera, Palo } \\
\text { Alto y las quebradas La Zumbona, Aserrío } \\
\text { y Agustín }\end{array}$ & $\begin{array}{l}\text { Un saldo de } 135 \text { personas damnificadas y } \\
10.000 \text { afectados aproximadamente; } 4 \text { hoteles y } \\
40 \text { casas sufrieron daños. Además hubo daños } \\
\text { en el puente sobre el río Palo Alto y en } 18 \text { pun- } \\
\text { tos del muro de canalización del río Caldera. }\end{array}$ \\
\hline 2011 & $\begin{array}{l}\text { Septiembre } \\
26\end{array}$ & $\begin{array}{l}\text { Desbordamiento de la quebrada La Zum- } \\
\text { bona. }\end{array}$ & $\begin{array}{l}\text { Colapsa el puente sobre la quebrada La } \\
\text { Zumbona. Se afectan } 20 \text { mil habitantes de las } \\
\text { comunidades de Los Naranjos, Los Jarami- } \\
\text { llos, Palo Alto, Bajo Boquete. }\end{array}$ \\
\hline
\end{tabular}

Elaboración propia con base en los registros de la UNIVERSIDAD DE PANAMÁ (1990); SOLÍS \& CUEVAS (1995), DESINVENTAR (2014).

\section{MATERIALES Y MÉTODOS}

Esta investigación se basa en el método científico a partir de los métodos inductivodeductivo, analítico-sintético y analíticosociológico. Se estableció el marco teórico a partir de la Teoría de Sistemas Sociales (LUHMANN 1998) y el marco conceptual desde dicha teoría y de la perspectiva de la Geografía de los Riesgos, con la finalidad de demostrar la hipótesis referida a que la participación ciudadana es un elemento que determina la eficacia de la gestión local de riesgo por inundación como proceso social sistémico y complejo, dentro de un sistema social, y que contribuye a la reducción del riesgo de desastres en un espacio local.

Para ello se analizaron e indujeron los aspectos teórico-conceptuales del riesgo de desastres, abordando diferentes enfoques y propuestas de éstos para el análisis de las amenazas, la vulnerabilidad y el desastre. Se profundizó en la diferenciación de los conceptos gestión del riesgo, gestión del riesgo de desastres y gestión local del riesgo de desastres. De la inducción gestión del riesgo de desastres se identifican sus dimensiones, las fases y se describió sus enfoques y modelos. Posteriormente, a partir de este análisis se sintetizan las dimensiones, las fases y los modelos que deben integrar a la gestión local del riesgo por inundación; asimismo, se deducen sus características, elementos y su naturaleza geográfica como primera aportación del presente documento.

A través de la sociológica Teoría de los Sistemas Sociales y los planteamientos conceptuales desde la perspectiva geográfica humana, se construyó y problematizó el objeto de estudio, la gestión local del riesgo por inundación, hasta construir la naturaleza 
geográfica de la misma. Se identificó y analizó la comunicación entre los subsistemas del sistema social que afectan la eficacia de la gestión local del riesgo por inundación. De este marco teórico se recuperan conceptos como sistema, subsistema y actor social, con la finalidad de lograr problematizar al fenómeno y determinar la entropía (desorden) que los subsistemas mantienen dentro del sistema social del distrito de Boquete, debido a la comunicación compleja de los subsistemas geográfico físico, geográfico humano, histórico, económico, político, cultural y jurídico.

Atendiendo a estas consideraciones, se presenta el caso de la subcuenca del río Caldera a partir de un análisis sintéticosociológico de la realidad del sistema social del distrito de Boquete y la afectación sistémica y por tanto, entrópica de la gestión local de riesgo por inundación desde 2008 a 2013, además de resaltar la necesidad de la existencia del subsistema participación ciudadana para la eficacia en la misma.

\section{RESULTADOS}

\section{La gestión local del riesgo por inundación}

La construcción conceptual de la gestión local del riesgo por inundación parte de la inducción y análisis de los términos riesgo de desastres y gestión pública del riesgo de desastres. Dentro de este marco, la gestión local del riesgo por inundación tiene dos perspectivas: las acciones mismas para afrontar el riesgo de desastres y la dinámica del sistema social y sus subsistemas que determinan su eficacia. Para ello es necesario inducir en los aspectos teóricos-conceptuales de la gestión del riesgo de desastres en general (Fig. 2), contextualizarlo, llegar a su aplicación práctica en el sistema social y a su vez considerar los elementos de los subsistemas que inciden en la comunicación para lograr la eficacia del sistema de gestión local del riesgo por inundación. En consecuencia a esta afirmación, se identificaron las principales características y los elementos

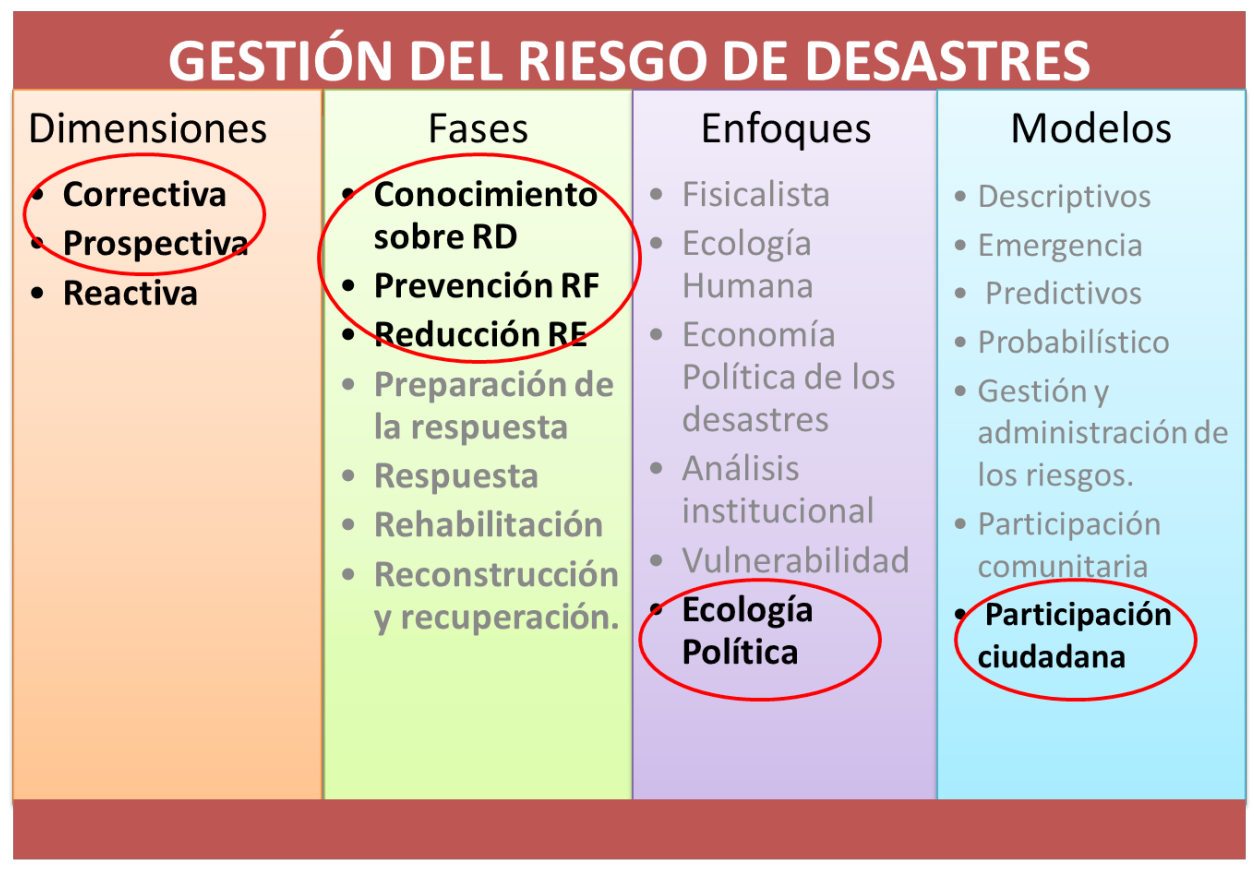

Fig. 2. Aspectos teórico-conceptuales de la gestión del riesgo de desastres. 
que conforman la gestión local del riesgo por inundación para obtener la esencia conceptual y su función, resaltando la participación ciudadana como uno de los elementos trascendentales que pretende asegurar su eficacia y que por ende conlleva a la reducción del riesgo de desastre existente y a evitar riesgos futuros.

Características de la gestión local del riesgo por inundación

De las características del riesgo de desastres y de la gestión pública del riesgo de desastres, se deduce que la gestión local del riesgo por inundación es un proceso sistémico que está compuesto por diversos elementos relacionados entre sí. Tal relación es de carácter horizontal, ya que sus elementos son interdependientes conservando su autonomía y descentralización en sus funciones, responsabilidades y el accionar de todas las fases del riesgo por inundación. De todo esto se desprende que debe haber una integración, coordinación y comunicación que garantice el cumplimiento del fin último de la gestión, sea este reducir y evitar el incremento del riesgo por inundación.

Como proceso sistémico, la gestión local de riesgo por inundación es un sistema social complejo que se desarrolla en un subsistema geográfico humano del sistema social y se caracteriza por su auto-organización y auto-referenciación. Estas características permiten inferir que el sistema como tal, por su autoconocimiento, puede encontrar las causas de origen que no permiten la existencia de una gestión del riesgo por inundación eficaz. En este sistema, la auto-organización y auto-referenciación permiten que exista una comunicación que no debe romperse, por lo tanto se deben prevenir y evitar la entropía y la irritabilidad generadas muchas veces por el entorno y que afecta a los elementos que la conforman y que conforman sus subsistemas. Como consecuencia requiere que sea un proceso organizacional y sistemático que analice el papel de cada uno de los elementos que componen el sistema social al que pertenezca el sistema de gestión local del riesgo por inundación, el funcionamiento de este sistema, la dinámica de trabajo de los actores y la eficiencia de estos en todas las fases del riesgo de desastre. Aquí se toman en consideración aspectos administrativos que conllevan a una gestión eficaz.

La gestión local del riesgo por inundación, una vez conocida y reconocida en su funcionamiento, podrá ser parte fundamental de los planes estratégicos de desarrollo nacional que tienen aplicación en el ámbito local o que emergen de la planificación local, ello como parte del trabajo realizado por todos los actores locales en coordinación con la escala regional y nacional en los que se realiza un diagnóstico, donde se identifican las cualidades y características de las estrategias de desarrollo a implementar, y a partir de este consenso se asignan objetivos estratégicos, se elabora una estrategia de desarrollo local y las recomendaciones de acciones específicas, a través de proyectos y/o políticas que permitan alcanzar los objetivos en función de las cualidades detectadas como necesarias en la gestión del riesgo por inundación.

Debido a lo anterior y aplicado al caso de la subcuenca del río Caldera en el distrito de Boquete, se considera necesario que la gestión local del riesgo por inundación forme parte de los planes de ordenamiento territorial, que no permitan la expansión de la mancha urbana hacia zonas de alto riesgo por inundación o dentro de las terrazas de inundación de los afluentes que conforman la subcuenca del río Caldera, por lo que es indispensable crear un marco institucional normativo sobre la base de elementos que regulen jurídicamente su creación y constitución; ello a partir del análisis sistémico del subsistema normativo que durante el periodo 2008-2013 regula jurídicamente en el distrito de Boquete. Como consecuencia, este marco no puede ignorar las estructuras, normatividad y 
sistemas interinstitucionales en la escala regional, nacional e internacional, las cuales avalan las acciones de la gestión del riesgo por inundación, promueven estrategias, estimulan el buen funcionamiento y ofrecen financiamiento para su funcionamiento.

Elementos que conforman la gestión local del riesgo por inundación (Fig. 3)

Por lo que respecta a la dimensión espacial de aplicación y organización, la gestión local del riesgo por inundación tiene un sentido territorial, pues dependiendo del país y el programa que se esté desarrollando se establece la clasificación espacial. La clasificación para el caso específico de Panamá puede estar referida a las áreas de comunidades pequeñas de un mismo municipio, una región que abarca más de un municipio o parte de ellos. La clasificación no hace referencia a las dimensiones de las áreas y regiones, la delimitación tiene que ver con el radio de afectación territorial de la amenaza, más que por los límites administrativos existentes, ya que no es una delimitación espacial administrativa. Para la presente investigación, el espacio local abarca el distrito de Boquete, específicamente la subcuenca del río Caldera.

Por otro lado, como deducción y síntesis principal de la naturaleza geográfica se determina indispensable, para que exista la gestión local del riesgo por inundación, la participación ciudadana. Esta se conforma de algunos elementos o subsistemas sociales como la acción dinámica e integral de los habitantes de una comunidad, las organizaciones gubernamentales y no gubernamentales, relacionados y coordinados con los actores regionales, nacionales e internacionales. La participación ciudadana no debe confundirse con la participación popular, la participación social, la participación comunitaria o la participación política (CUNILL 1991), pues son formas distintas de acción de los actores sociales.
En la participación ciudadana, los actores sociales deben involucrarse en la gestión del riesgo por inundación para reducir de manera sostenible e integrada el riesgo existente en la población local. La ausencia de alguno de los actores locales disminuye la eficacia de la gestión. Para ello es importante que la integración de los actores locales en el proceso de la gestión del riesgo, se lleve a cabo identificando a los actores claves, liderados por la administración municipal (Fig. 4).

Cabe considerar que la participación ciudadana debe responder a un proceso de planificación participativa dentro de la gestión local del riesgo por inundación. Este proceso debe desarrollarse en forma continua y con una reflexión crítica de todos los actores que lo conforman; por ello, se precisa identificar cuáles son las funciones y responsabilidades concretas de cada uno de los actores, además se debe recoger las ideas y supuestos de cómo observan estos la gestión del riesgo por inundación, qué se ha realizado para enfrentar fenómenos cotidianos o extremos por inundación y cuáles son los resultados alcanzados.

En este proceso de planificación, los actores locales que participan en la gestión local del riesgo por inundación deben identificar sus necesidades, demandas, posibles soluciones y prioridades que se presentan en todas las fases del riesgo. Esto implica considerar las estrategias dentro de la gestión correctiva, prospectiva y reactiva del riesgo de desastres. En consecuencia, este proceso de planificación debe generar un Plan de Gestión Local del Riesgo por Inundación que sea eficaz y que contemple no sólo las fases de la gestión local del riesgo de desastres (conocimiento del riesgo de desastres, prevención del riesgo futuro, reducción del riesgo existente, preparación de la respuesta, respuesta, rehabilitación y reconstrucción y recuperación del sistema social), sino que señale también los instrumentos de gestión que serán utilizados en la planificación. 


\section{La gestión local del riesgo por inundación}

\section{Elementos}

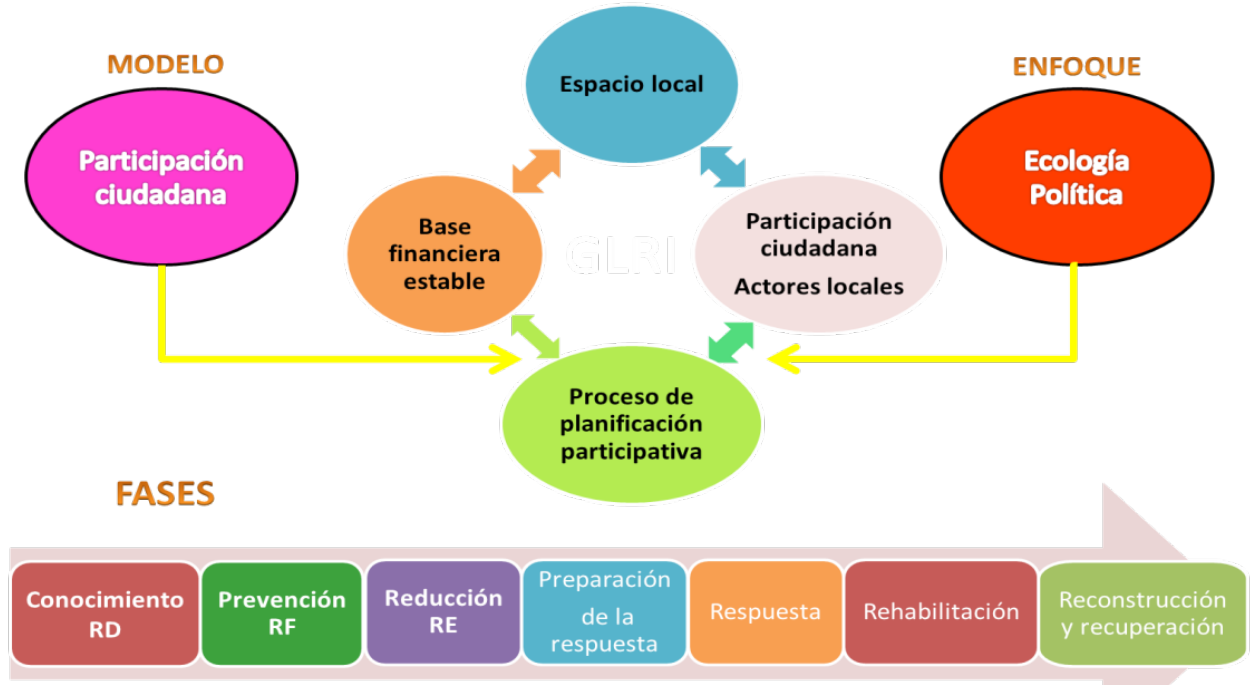

Fig.3. Gestión local del riesgo por inundación.

\begin{tabular}{|c|c|c|c|c|c|c|}
\hline $\begin{array}{l}\text { Autoridades } \\
\text { locales }\end{array}$ & $\begin{array}{c}\text { Organismos } \\
\text { de } \\
\text { seguridad }\end{array}$ & $\begin{array}{c}\text { Sector } \\
\text { educativo y } \\
\text { eclesiástico }\end{array}$ & $\begin{array}{l}\text { Institucio- } \\
\text { nes } \\
\text { guberna- } \\
\text { mentales }\end{array}$ & $\begin{array}{l}\text { Organizaciones no } \\
\text { Gubernamentales }\end{array}$ & Sector privado & $\begin{array}{l}\text { Líderes no } \\
\text { formales }\end{array}$ \\
\hline $\begin{array}{l}\text { - Alcalde } \\
\text { Municipal } \\
\text { - HR. De } \\
\text { corregimient } \\
\text { os } \\
\text { - Corregidores } \\
\text { - Junta de } \\
\text { Planificación } \\
\text { - Juntas } \\
\text { Comunales }\end{array}$ & $\begin{array}{l}\text { - SINAPROC } \\
\text { - Cruz Roja } \\
\text { - Cuerpo de } \\
\text { Bomberos } \\
\text { - Policía } \\
\text { Nacional } \\
\text { - Sistema } \\
\text { Único de } \\
\text { Manejo de } \\
\text { Emergencias } \\
\text { 9-1-1 }\end{array}$ & $\begin{array}{l}\text { - Supervisor de } \\
\text { zona escolar. } \\
\text { - Directores de } \\
\text { Escuelas } \\
\text { Secundarias } \\
\text { - Directores de } \\
\text { escuelas y } \\
\text { colegios } \\
\text { particulares. } \\
\text { - Representante } \\
\text { de la Iglesia } \\
\text { Católica } \\
\text { - Representantes } \\
\text { de las iglesias. } \\
\text { - Lirio del Valle. }\end{array}$ & $\begin{array}{l}\text { - MINSA } \\
\text { - CSS } \\
\text { - MOP } \\
\text { - MDA } \\
\text { - ANAM } \\
\text { - IDIAP } \\
\text { - BDA } \\
\text { - CA } \\
\text { - BN }\end{array}$ & $\begin{array}{l}\text { - ADIB } \\
\text { - Asociación de } \\
\text { Ambientalistas Comité } \\
\text { Administrativo de } \\
\text { Acueducto Rural de } \\
\text { Palo Alto y } \\
\text { Mejoramiento de la } \\
\text { Comunidad } \\
\text { (CARPAMEC). } \\
\text { - Comité de acueducto } \\
\text { de Jaramillo Arriba. } \\
\text { - Asociación de } \\
\text { beneficiadores y } \\
\text { exportadores de café. } \\
\text { - Feria de las Flores y el } \\
\text { Café. } \\
\text { - Club Rotary } \\
\text { - Club 20-30 } \\
\text { - Club de Leones } \\
\text { - Amigos de Boquete } \\
\text { - Damas Rosadas } \\
\text { - 3a edad y jubilados } \\
\text { - RealBoquete }\end{array}$ & $\begin{array}{l}\text { - Cámara de Turismo de } \\
\text { Boquete. } \\
\text { - Comerciantes } \\
\text { - Cooperativas de } \\
\text { Ahorro y Créditos: } \\
\text { CACSA, } \\
\text { TRANSBURSA } \\
\text { - Rivera }\end{array}$ & $\begin{array}{l}\text { - Líderes } \\
\text { dentro de los } \\
\text { corregimientos } \\
\text { - Personas } \\
\text { afectadas por } \\
\text { inundaciones } \\
\text { - Pueblos } \\
\text { originarios. } \\
\text { - Residentes } \\
\text { extranjeros } \\
\text { - Localidades } \\
\text { : } \\
\text {-Bajo Mono } \\
\text {-Los Naranjos } \\
\text {-Cabecera } \\
\text {-Wilson } \\
\text {-Palo Alto } \\
\text { Los Jaramillo } \\
\text { (Qda. La } \\
\text { Zumbona) } \\
\text {-Arco Iris } \\
\text {-Qda. Agustín }\end{array}$ \\
\hline
\end{tabular}

Fig.4. Actores claves en el proceso de gestión del riesgo. 
Considerando que todo proceso de gestión requiere recursos humanos, técnicos y económicos, dentro de la gestión local del riesgo por inundación se debe asegurar una apropiada organización, más que requerir de cuantiosos recursos monetarios. Los recursos deben provenir de todos los actores involucrados y no concentrarse en una sola entidad gubernamental o no gubernamental. Todos deben aportar para mantener estable y con un funcionamiento eficaz a la gestión local del riesgo por inundación, ya sea en recursos humanos que son los encargados de la administración de la gestión. Los técnicos que se especializan en un campo determinado, sugieren medidas y estrategias estructurales o no estructurales y los recursos económicos necesarios en toda organización para el funcionamiento, compra de materiales, capacitación, prevención y obras para mitigación, entre otras. Todo esto con el fin de reducir el riesgo por inundación y que se evite que se presenten otros riesgos en la subcuenca del río Caldera.

Naturaleza geográfica de la gestión local del riesgo por inundación y su función

Las características y elementos señalados en los párrafos anteriores permitieron determinar la esencia y la naturaleza organizacional de la gestión local del riesgo por inundación. En este sentido, la gestión local del riesgo por inundación se concibe como un sistema complejo, organizacional, localizada en un espacio local, integrada por procesos de desarrollo local, con estructuras normativas sólidas y descentralizadas. Requiere como elemento fundamental la participación ciudadana de los actores locales, a través de un proceso de planificación participativa que contemple recursos humanos, técnicos y económicos, a fin de cumplir su función de establecer y ejecutar políticas, medidas y estrategias concretas que fortalezcan las capacidades de prevención y afrontamiento del riesgo local ocasionado por el impacto de las inundaciones cotidianas o extremas y que reduzca la posibilidad de que ocurra un desastre. Cabe destacar que sin la existencia de uno de sus elementos constitutivos, no puede existir la gestión local del riesgo y se genera la entropía dentro del sistema de la gestión y del sistema social en el que se desarrolle.

A través de la esencia y función de la gestión local del riesgo por inundación, se logra identificar los principales subsistemas sociales del distrito de Boquete que afectan directamente la eficacia de la gestión en la subcuenca del río Caldera y por lo tanto condicionan su comportamiento.

\section{Subsistemas que conforman el sistema social. El caso de la subcuenca del río Caldera en el Distrito de Boquete, Panamá}

Como se mencionó anteriormente, la subcuenca del río Caldera, por sus características geológicas e hidrometeorológicas, es una zona de multi-amenazas. Para efectos de la presente investigación, por el grado de afectación a la población y las pérdidas económicas ocasionadas, se seleccionó como fenómeno específico a las inundaciones. En este caso es necesario considerar los subsistemas del sistema social del distrito de Boquete y sus elementos constitutivos al momento de aplicar un modelo de gestión del riesgo por inundación en el ámbito local, dado que existe un riesgo que se debe conocer y gestionar. En este sentido se presentan los principales subsistemas que afectan la eficacia de la gestión local del riesgo por inundación en el distrito de Boquete (Fig. 5). Cabe señalar que se utilizará el término sistema en cada uno de los subsistemas de análisis, ya que al desprenderse y analizarse de manera independiente conforman un sistema con sus elementos propios.

A este respecto se hace referencia al sistema geográfico-físico, que presenta una complejidad al igual que la región centroamericana. Los elementos del 
sistema físico tienen una dinámica propia que aumenta su complejidad y es determinante para que la subcuenca del río Caldera se convierta en una zona vulnerable a la ocurrencia de fenómenos naturales cotidianos y extremos, en este caso de inundación y que aunado a la acción antrópica incide en la gestión local del riesgo por inundación.

En este estudio, el sistema geográfico-físico está relacionado con la amenaza, inundación, y vulnerabilidad, características del sistema social que pueden ser dañados por la amenaza (UNITED NATIONS OFFICE FOR DISASTER RISK REDUCTION 2009), los cuales son los componentes del riesgo de desastre. La amenaza es la probabilidad de que un hecho geográficofísico se transforme en un fenómeno natural que genere un daño sobre poblaciones humanas. La amenaza por inundación que se presenta en la subcuenca del río Caldera es de origen socio-natural ya que como se expresó anteriormente, se genera por la dinámica de la naturaleza relacionada $\mathrm{y}$ condicionada por las actividades antrópicas que se desarrollan en la subcuenca y a nivel de la región.

Puesto que los fenómenos naturales no son en sí causantes de los desastres, sino que existen factores sociales que se comunican e influyen para que aumenten los niveles del riesgo y este se materialice, es importante analizar el sistema geográfico-humano, considerado un elemento híbrido en conjunto con el factor físico, por la Geografía de los Riesgos. Aunque los sistemas geográficofísico y geográfico-humano se analizan de manera independiente, no son ajenos entre sí, ya que se desarrollan en un mismo espacio físico y social.

Del sistema geográfico-humano se detectan aquellos elementos que inciden en el incremento del riesgo por inundación en la subcuenca del río Caldera, por ejemplo: la distribución espacial, dinamismo, tamaño y características de la estructura poblacional; las actividades económicas preponderantes en el área; la estructura político-administrativa local del distrito de Boquete ya que la gestión del riesgo está determinada por instituciones públicas.

En el sistema geográfico-humano, una serie de factores se conjugan para que pueda implementarse la gestión local del riesgo por inundación. Aunque la realidad social en el distrito de Boquete no es distinta a la de otras regiones de Centroamérica, los aspectos institucionales, jurídicos y culturales marcan la diferencia en cuanto a la viabilidad de este tipo de gestión del riesgo. Dichos factores han obstaculizado que en la subcuenca del río Caldera exista una gestión del riesgo por inundación adecuada y eficaz. En este caso se observa que por la falta de políticas públicas, mecanismos institucionales y de participación ciudadana adecuados, no se ha logrado reducir los riesgos existentes y evitar los riesgos futuros, lo cual se traduce en la falta de comunicación entre los sistemas político y geográfico-humano, lo que influye y condiciona la ineficacia de la gestión local del riesgo por inundación en Centroamérica.

Para explicar por qué no existe una gestión local del riesgo por inundación adecuada para la subcuenca del río Caldera, es necesario abordar desde un modo sistémico las estructuras sociales de la localidad y la interacción con el sistema de geografía física. Por ejemplo, en la estructura histórica se debe revisar el proceso de colonización local, las características poblacionales y las áreas de concentración humana. Una de las características de la estructura poblacional que presenta la subcuenca del río Caldera en los últimos 15 años, es que algunos de los habitantes provienen de las comunidades de pueblos originarios, como la Comarca Ngäbe Buglé y de poblaciones extranjeras, de manera que el incremento poblacional en las últimas tres décadas ha sido impulsado tanto por la inmigración interna como externa. Según los censos poblacionales 
de Panamá, para 1990 la población en el distrito de Boquete era de 14.126 habitantes; para el 2000, de 16.943; y para el 2010, de 21.370. Estas cifras indican un crecimiento de $16 \%$ entre la década de 1990-2000 y de $21 \%$ con respecto a la década 2000 2010 (INSTITUTO NACIONAL DE ESTADÍSTICA Y CENSO DE LA REPÚBLICA DE PANAMÁ 2010). Este crecimiento poblacional ha generado la expansión del área urbana hacia áreas de alto riesgo de inundación. Muchas viviendas, infraestructura urbana e instalaciones para servicios turísticos han sido construidas en las terrazas de inundación del río Caldera o de alguno de sus afluentes, sobre todo de los residentes extranjeros con un poder adquisitivo mayor (Fig. 6).

Respecto a la estructura económica, también se ha determinado la existencia de la gestión del riesgo por inundación en la subcuenca del río Caldera. En el presupuesto de ingreso del Municipio de Boquete, instancia político-administrativa que tiene jurisdicción sobre el área de estudio, durante el período 2008-2013, según el ex-Alcalde del distrito Manolo Ruiz $^{4}$, no existió un renglón específico para gestionar el riesgo de desastres. Del presupuesto general se aprueban partidas para dar atención a un desastre natural, en caso de que ocurra; cuando se sobrepasa el límite financiero local, la gestión pasa al nivel regional a través de la Gobernación de la Provincia y de éste, al nivel nacional. También mediante la activación del Centro de Operaciones de Emergencia de la Región Occidental de Chiriquí, se gestionan recursos para dar repuesta ante un desastre dentro del distrito de Boquete. Este hecho constituye un problema serio, ya que no existe un presupuesto que contemple todas las fases del riesgo, en un plan integral de gestión del riesgo por inundación.

En cuanto al sistema económico, se refleja un crecimiento de la actividad económica local vinculado con el aumento poblacional. Aunque se considera positivo este aumento de la economía local, las actividades económicas dejan de lado temas importantes como la gestión del riesgo de desastres. Como consecuencia, a pesar de que la actividad económica se ve afectada por inundaciones periódicas, la capacidad de reconstrucción consume un amplio porcentaje de los recursos económicos locales existentes. Esos recursos se gastan en la rehabilitación, reconstrucción y recuperación de las construcciones afectadas y muy poco en políticas de prevención, en estudios de ordenamiento territorial $\mathrm{y}$ en investigaciones prospectivas para determinar la probabilidad de amenazas futuras. Este es uno de los procesos causales de la ineficacia de las políticas de gestión del riesgo de desastres.

Por otro lado, en la estructura política es notable la ausencia de mecanismos de ampliación de la gobernanza. Existe un diseño inapropiado de políticas públicas de gestión del riesgo que han impedido actuar frente a las amenazas y los riesgos por inundación en la subcuenca del río Caldera. Asimismo, el modelo de gestión del riesgo de desastres excluye del proceso a uno de los actores principales, la ciudadanía. En la actualidad, la gestión del riesgo en el distrito de Boquete y en particular para la subcuenca del río Caldera se lleva a cabo siguiendo el modelo de emergencia de corte vertical, en donde toda la responsabilidad recae en el Sistema Nacional de Protección Civil, con la participación limitada de las autoridades locales, quienes intervienen sólo en caso de presentarse la emergencia. La aplicación de este modelo tiene la limitante de que las directrices planteadas en la normativa no llegan hasta el nivel local y no se hace efectiva la política pública nacional e internacional, ya que Panamá se rige por la Política Centroamericana de Gestión Integral del Riesgo de Desastres, adoptada en 2011. Inclusive, no existen planes de emergencia municipal, o de emergencia ambiental.

\footnotetext{
4 Entrevista realizada el 24 de octubre de 2013.
} 
Tanto el Sistema Nacional de Protección Civil como las autoridades locales y los organismos gubernamentales se activan cuando un fenómeno natural impacta en una comunidad. Al ocurrir esto, la falta de participación ciudadana atenta contra la eficacia en la aplicación de las políticas públicas, de forma sistemática y siguiendo el sistema jurídico en cuanto hace a su sistema normativo en materia de gestión local del riesgo. La participación ciudadana debe ocurrir en todas las fases de la gestión del riesgo de desastres, para que se pueda cumplir con la función social de este tipo de políticas.

Por otra parte, el sistema antropológico, respecto a la filosofía de pensamiento representado por el ámbito cultural de poblaciones asentadas en las zonas de afectación del río Caldera, es determinante para implementar una política de gestión local del riesgo por inundación. Una política de este tipo obliga a realizar un análisis del conocimiento, creencias y prácticas sociales de los pobladores en áreas de alto riesgo.

Se debe considerar las diferencias culturales que llevan a interpretaciones diferentes de cómo es el riesgo por inundación y cómo debe darse la organización ciudadana para participar en una situación de desastre.

La estructura cultural es igual de compleja que los sistemas anteriores, ya que los actores sociales afectados por un desastre interpretan de manera distinta las acciones de prevención, rehabilitación o salvaguarda de vidas y bienes materiales.

El sistema jurídico, conformado por los instrumentos normativos vigentes en Panamá, establece políticas públicas verticales y centralizadas que no permiten el cumplimiento de los objetivos de un modelo de gestión del riesgo de desastres con participación ciudadana.
En la práctica, la ejecución de la gestión del riesgo de desastres no se replica en el ámbito local. Por ejemplo, el Decreto Ejecutivo $\mathrm{N}^{\circ} 177$ de 2008 que reglamenta el Sistema Nacional de Protección Civil y que contempla dentro de sus finalidades promover la participación ciudadana en el proceso de gestión del riesgo, también establece desarrollar estrategias para incorporar a los municipios y comarcas más vulnerables en el análisis de los riesgos y asimismo establece los derechos y obligaciones de los ciudadanos en materia de protección civil, pero esto no se observa en la subcuenca del río Caldera, una de las áreas más vulnerables del país.

De igual manera se puede detectar la falta de aplicación de la norma en cuanto a lo que establece el Decreto Ejecutivo $\mathrm{N}^{\circ}$ 1101 del 30 de diciembre de 2010, por la que se aprueba la Política Nacional de Gestión Integral de Riesgo de Desastres. Lo mismo ocurre con el Plan Nacional de Gestión de Riesgo de Desastres de la República de Panamá (2011-2015), en donde se enfatiza la gestión local del riesgo y el reconocimiento de los factores causales del riesgo, tanto físicos como de vulnerabilidad; plantea la desconcentración y descentralización del Sistema Nacional de Protección Civil de Panamá, al involucrar la participación de la población y la coordinación interinstitucional, intersectorial y multidisciplinaria; además garantiza la participación de la sociedad civil en el proceso de toma de decisiones para la reducción del riesgo. De aquí que estos propósitos estén ausentes cuando ocurre un desastre por inundación en la subcuenca del río Caldera. Todo esto es un indicativo de la disfunción de la gestión del riesgo de desastres que impera en Panamá. 


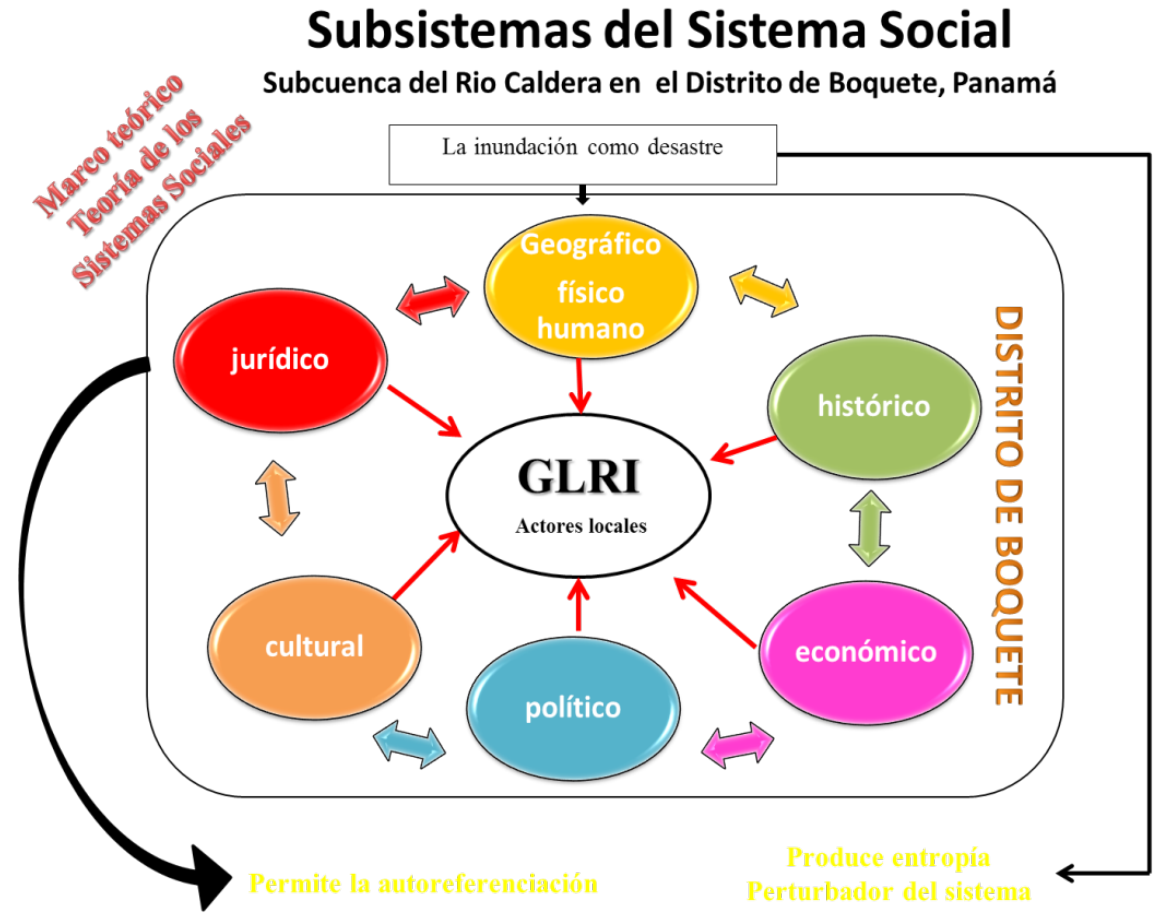

Fig. 5. Subsistemas del sistema social.

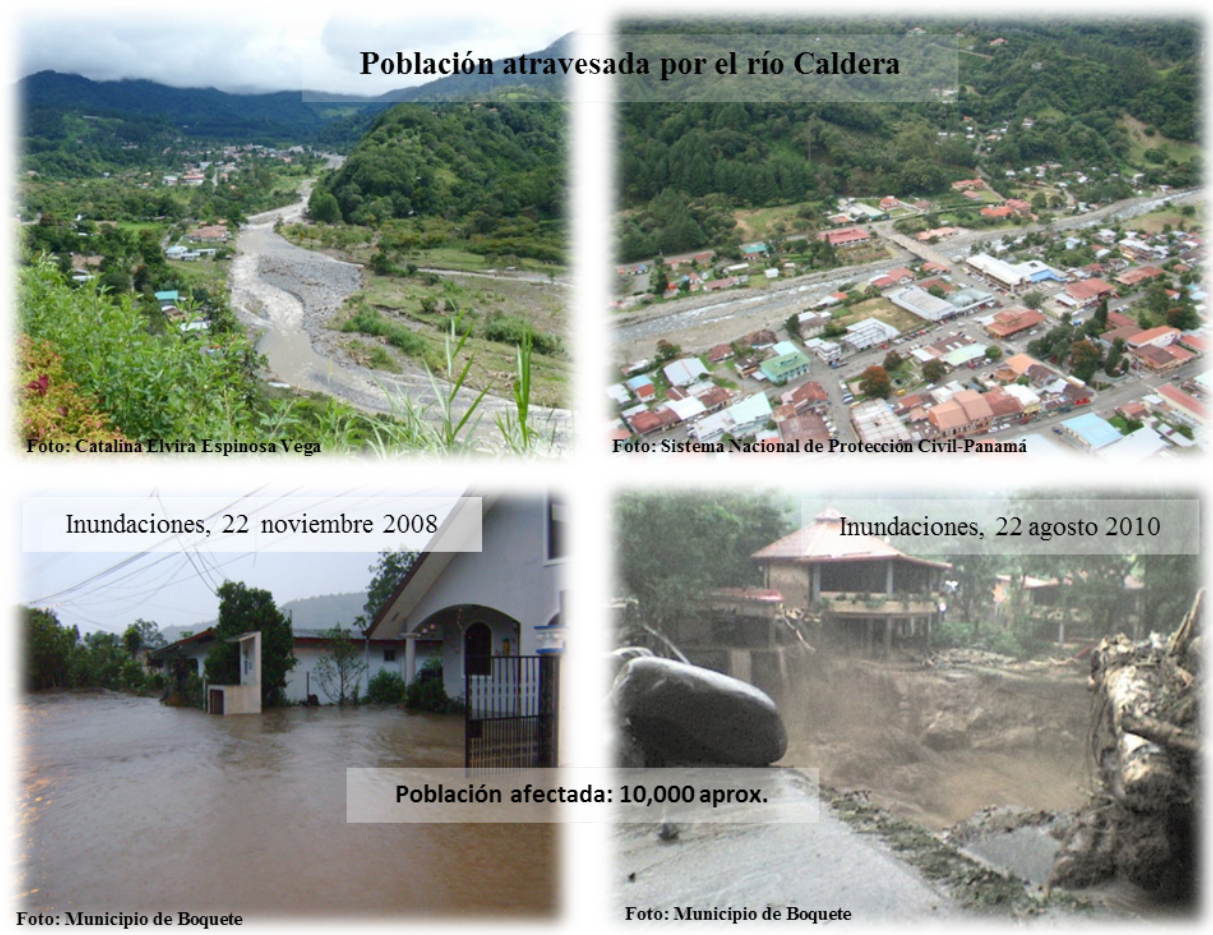

Fig. 6. Áreas de inundación en el río Caldera. 


\section{DISCUSIÓN}

Los resultados presentados permiten determinar la evolución de los postulados conceptuales de la gestión local del riesgo de desastres en los últimos 14 años, hasta considerar la gestión local del riesgo, además de enfoque o modelo, como un proceso sistémico que adquiere una complejidad tal y que es deducible desde sus modos de operación dentro del sistema social, ya que tiene características propias que la distinguen y elementos que la constituyen. De aquí se desprende la esencia o naturaleza desde el punto de vista geográfico de la gestión local del riesgo por inundación, para conocer el funcionamiento del sistema del cual forma parte, evaluar la afectación y condicionamiento como resultado de la comunicación que desarrollan los sistemas que conforman el sistema social, establecer la relación con su entorno y a su vez determinar cómo estos sistemas afectan la eficacia de la gestión local del riesgo por inundación. Para llegar a esta valoración y conceptualización de la gestión local del riesgo por inundación como proceso sistémico, se debe considerar la amplitud de su terminología e iniciar el proceso inductivo desde los términos gestión del riesgo y gestión del riesgo de desastres, para deducir sus dimensiones, fases, enfoques, modelos, características y naturaleza.

El conocimiento profundo de las bases conceptuales de la gestión local del riesgo por inundación, a través de la Geografía de los Riesgos, contribuyó a identificar y analizar los elementos del sistema social que inciden en el riesgo por inundación del área de estudio. También se conoció la gestión del riesgo de desastres desarrollada desde 2008 hasta 2013. Este conocimiento permite proponer estrategias que conlleven el desarrollo de medidas de reducción del riesgo de desastres por inundación, estructurales y no estructurales, al mismo tiempo permite identificar las causas de fondo del desastre por inundación en las estructuras del sistema social y que no se consideran dentro de las políticas públicas que deben ejecutar los tomadores de decisiones para un espacio territorial determinado, con la contribución de todos los actores locales y en coordinación con otras escalas. Asimismo, este conocimiento permite aumentar la resiliencia por el riesgo de inundación mediante la información científica y considerando las estructuras sociales del distrito de Boquete, como la geográfica, histórica, económica, política, cultural y jurídica, y su influencia en la eficacia de la gestión local del riesgo por inundación.

De esta forma se deduce que la gestión local del riesgo por inundación constituye una de las estrategias que contribuyen a la reducción de este riesgo. Sin embargo, se requiere motivar a los actores locales para lograr su aplicación, especialmente a las autoridades locales que les compete por ley desarrollar estrategias de gestión local del riesgo de desastres. En ese mismo sentido, la gestión local del riesgo por inundación conlleva que se adopten y apliquen medidas considerando la opinión de todos los actores claves y así asegurar que las directrices sean adecuadas en un momento y lugar determinados. Esta situación demanda de un conocimiento del espacio local del área en el cual se desarrolla y sobre todo requiere realizar actividades que eviten el aumento o el desarrollo de nuevos riesgos de desastres, denominada por muchos investigadores como la gestión prospectiva del riesgo de desastres.

A pesar de estas afirmaciones, se ha generado en la región centroamericana un conocimiento sobre la gestión local del riesgo de desastres, inclusive con especialistas, autoridades y organismos de seguridad de Panamá, pero su aplicación y acción aún no se evidencia en las áreas propensas al riesgo por inundación. Estas razones demuestran que las políticas de prevención del riesgo de desastres se apoyan en modelos de gestión del riesgo en los que la participación ciudadana está ausente, lo cual deriva en el diseño de estrategias y 
selección de mecanismos poco eficientes para reducir el riesgo por inundación existente y evitar los riesgos futuros.

Por otra parte, se enfatiza que la gestión local del riesgo por inundación como proceso sistémico implica una relación directa con la gobernanza y las políticas públicas desarrolladas en todas las escalas territoriales. En todo caso, es importante señalar que se considera a los desastres desde una perspectiva sistémica, en función de todos los subsistemas que afectan a la gestión local del riesgo. Esta tesis se apoya en que los factores físicos y sociales tienen igual jerarquía e importancia. Sólo visto de esta manera es que el sistema social local puede cumplir con el objetivo de reducir el riesgo existente y evitar los riesgos futuros. Por consiguiente, como proceso sistémico dentro del sistema social, la gestión local del riesgo por inundación debe estar cohesionada con cada uno de sus subsistemas, de tal forma que un desastre no perturbe ni trastoque el funcionamiento total del sistema y provoque una entropía. El funcionamiento normal del sistema tiene que ver con la comunicación e interrelación entre los subsistemas y a su vez entre los diferentes actores (grupos sociales, instituciones públicas, instituciones privadas, organizaciones ciudadanas, entre otros).

En consecuencia, el desarrollo de estrategias de prevención del riesgo futuro y el diseño e implementación de planes y proyectos de gestión pública deben conducir a tomar decisiones encaminadas a normar y controlar los procesos del sistema social que contribuyan a la eficacia de la gestión local del riesgo por inundación. Debe permitir también el desarrollo de estrategias de prevención del riesgo por inundación existente y futura a través del diseño e implementación de planes y proyectos de gestión pública. Además, deben conducir a tomar decisiones encaminadas a normar, controlar los procesos perturbadores del sistema social y que dentro de la gestión local del riesgo se contemplen las causas de fondo de los desastres ocurridos.
Es importante considerar todas las fases para la gestión del riesgo de desastres, por lo cual hay que profundizar en los aspectos de prevención futura mediante el conocimiento del riesgo, lo que implica la identificación de las amenazas y la evaluación de las vulnerabilidades. Estas acciones son un indicativo de que la gestión del riesgo no es sinónimo de gestión de la emergencia (gestión del riesgo de desastres reactiva).

Aunque en la actualidad algunos planes de emergencia contemplan medidas preventivas, éstas quedan en una categoría inferior. Se debe resaltar estas consideraciones, ya que las amenazas pueden causar daños o perturbaciones en las actividades cotidianas de una sociedad, hasta el grado de transformar estructuras, de ahí que se las considera como un factor dentro de una gestión local del riesgo de desastres. Dada la importancia en la gestión local del riesgo de desastres de buscar las causas de fondo del problema y así poder establecer las estrategias que disminuyan los riesgos existentes y futuros, se debe analizar las diferentes amenazas que presenta una región o lugar $\mathrm{y}$, a partir de esta consideración, se pueden analizar las amenazas presentes en el subsistema geográfico que compone el sistema socioespacial específico.

\section{CONCLUSIONES}

La participación ciudadana es un elemento que determina la eficacia de la gestión local del riesgo por inundación como proceso social sistémico y complejo dentro de un sistema social, y esta gestión contribuye a la reducción del riesgo de desastres en un espacio local.

El Distrito de Boquete carece de una gestión local del riesgo por inundación en la subcuenca del río Caldera, ya que no está descentralizada y es inexistente la participación ciudadana a través de los 
actores locales. Además, las autoridades municipales desconocen la estimación del riesgo por inundación en el espacio local, a pesar de que se han realizado investigaciones en el área. Se registran inundaciones desde 1938 y los datos revisados permiten considerar el riesgo de desastre como un elemento del entorno que perturba la realidad social del área de estudio y provoca una entropía al aumentar el nivel del riesgo existente. Relacionado a lo anterior, se sostiene que la gestión local del riesgo de desastres puede contribuir en la disminución de los efectos del sistema social que no permiten la eficacia de la gestión local del riesgo por inundación, al involucrar a las comunidades locales y sus actores, lo que es considerado indispensable para que exista esta gestión.

En consecuencia, es fundamental la aplicación en la subcuenca del río Caldera, de una gestión local del riesgo para reducir el riesgo por inundación y evitar desastres futuros. La gestión local del riesgo por inundación como un proceso sistémico puede ser aplicado en la subcuenca del río Caldera, pues supera la carencia de instrumentos de planificación, la centralización de la gestión del riesgo de desastres, la falta de motivación de las autoridades gubernamentales y no gubernamentales, y sobre todo la falta de participación ciudadana en la toma de decisiones que conlleven a solucionar la problemática existente. Una gestión local del riesgo por inundación, considerando sus características y elementos constitutivos, permite identificar, analizar y determinar las causas de fondo (factores determinantes y mecanismos detonantes) de los desastres causados por las inundaciones. Además permite que la gobernanza y las políticas públicas se relacionen y se articulen, con el fin de reducir el riesgo existente y los riesgos futuros.

\section{AGRADECIMIENTOS}

Al Gobierno de México, a través de la Secretaría de Relaciones Exteriores, por la beca otorgada para la realización de los estudios doctorales de la Magíster en Geografía Catalina Elvira Espinosa Vega. Al Dr. Juan Carlos Arriaga Rodríguez, profesor e investigador de la Universidad de Quintana Roo, México, por dirigir y asesorar la tesis doctoral.

\section{REFERENCIAS}

ARGÜELLO, M., 2002. De Yucatán a Darién. Gestión local del riesgo en el Istmo Centroamericano. Universidad Nacional de Costa Rica. Recuperado de: www. desenredando.org.

BOLLIN, C., 2003. Gestión local de riesgo. Experiencia de América Central. GTZ, Eschborn.

CALVO GARCÍA TORNEL, F., 1984. La Geografía de los Riesgos. Revista Geocrítica IX. 54.

CUNILL, N., 1991. Participación ciudadana. Dilemas y perspectivas para la democratización de los Estados Latinoamericanos. Centro Latinoamericano de administración para el desarrollo. https:// 0 fdc 5 abb 62 cb 3 alasites. g o o g l e g r o u p s.com/site/ catedrawbouzadauba/home/Participacixn ciudadana_Cunill.pdf?attachauth $=\mathrm{ANo} \overline{\mathrm{Y}}$ 7 coHfjqL k- DHazJUBT8SI148vYT-vA IUxPGBNaihpni4AqxnzY

DESINVENTAR, 2014. Sistema de inventario de efectos de desastres. Corporación OSSO. Colombia. http://www. desinventar.org/es/ 
Empresa de Transmisión Eléctrica (ETESA), 2014. Datos históricos de temperatura $\left({ }^{\circ} \mathrm{C}\right)$. http://www.hidromet. com.pa/clima_historicos.php

GELLERT, G., 2012. El cambio de paradigma: de la atención de desastres a la gestión del riesgo. Boletín Científico Sapiens Research 2, 1: 13-17.

INSTITUTO NACIONAL DE ESTADÍSTICA Y CENSO DE PANAMÁ, 2010. Censos de Población y Vivienda de 1990 a 2010. http://www.contraloria.gob. pa/inec/.

LAVELL, A., 2009. Relationships between Local and Community Disaster Risk Management \& Poverty Reduction: A Preliminary Exploration. A Contribution to the 2009 ISDR Global Assessment Report on Disaster Risk Reduction.

LUHMANN, N., 1998. Sistemas sociales: Lineamientos para una teoría general. Trad. Pappe, S. y Erker, B.; coord. Torres, J. Edi. Rubí, Anthropos, Universidad Iberoamericana, Centro Editorial Javeriano. España.

MASKREY, A., 1989. El manejo popular de los desastres naturales. Estudios de vulnerabilidad y mitigación. ITDG. Lima, Perú.

OLIVER-SMITH, A., 2013. La metodología FORIN. Ponencia presentada en el Curso-Taller Internacional de Investigaciones Forénsicas de Desastres Relacionados con la Ocurrencia de Deslizamientos, Tuxtla, México.
ROGELIS, M., LAM, J. \& RAMÍREZ CORTÉS, F., 2014. Advances in Flood Risk Assessments for Data-Limited Changing Environments. $6^{\text {th }}$ International Conference on Flood Management, Sao Paulo, Brazil.

SOLÍS, H. \& CUEVAS, J., 1995. Modelización hidrológica e hidráulica en la cuenca del río Caldera. Centro Agronómico Tropical de Investigación y Enseñanza (CATIE) y el Instituto de Recursos Hidráulicos y Electrificación (IRHE). Panamá.

SUTTON, M. \& ANDERSON, E., 2010. Introduction to Cultural Ecology. United States of America: Alta Mira Press.

UNIVERSIDAD DE PANAMÁ, 1990. Desastres naturales y zonas de riesgo en Centroamérica: condiciones y opciones de prevención y mitigación. Instituto de Estudios Nacionales.

VAN DER WEERT, R., 2009. Flooding of the Caldera River. Report PUM mission to Panama, Boquete.

WILCHES-CHAUX, G., 1998. Auge, caída y levantada de Felipe Pinillo, mecánico y soldador o yo voy a correr el riesgo. Guía de LA RED para la gestión local del riesgo. Red de Estudios Sociales en Prevención de Desastres en América Latina

UNITED NATIONS OFFICE FOR DISASTER RISK REDUCTION, 2009. Terminology on Disaster Risk Reduction. Ginebra, Suiza. www.unisdr.org. 


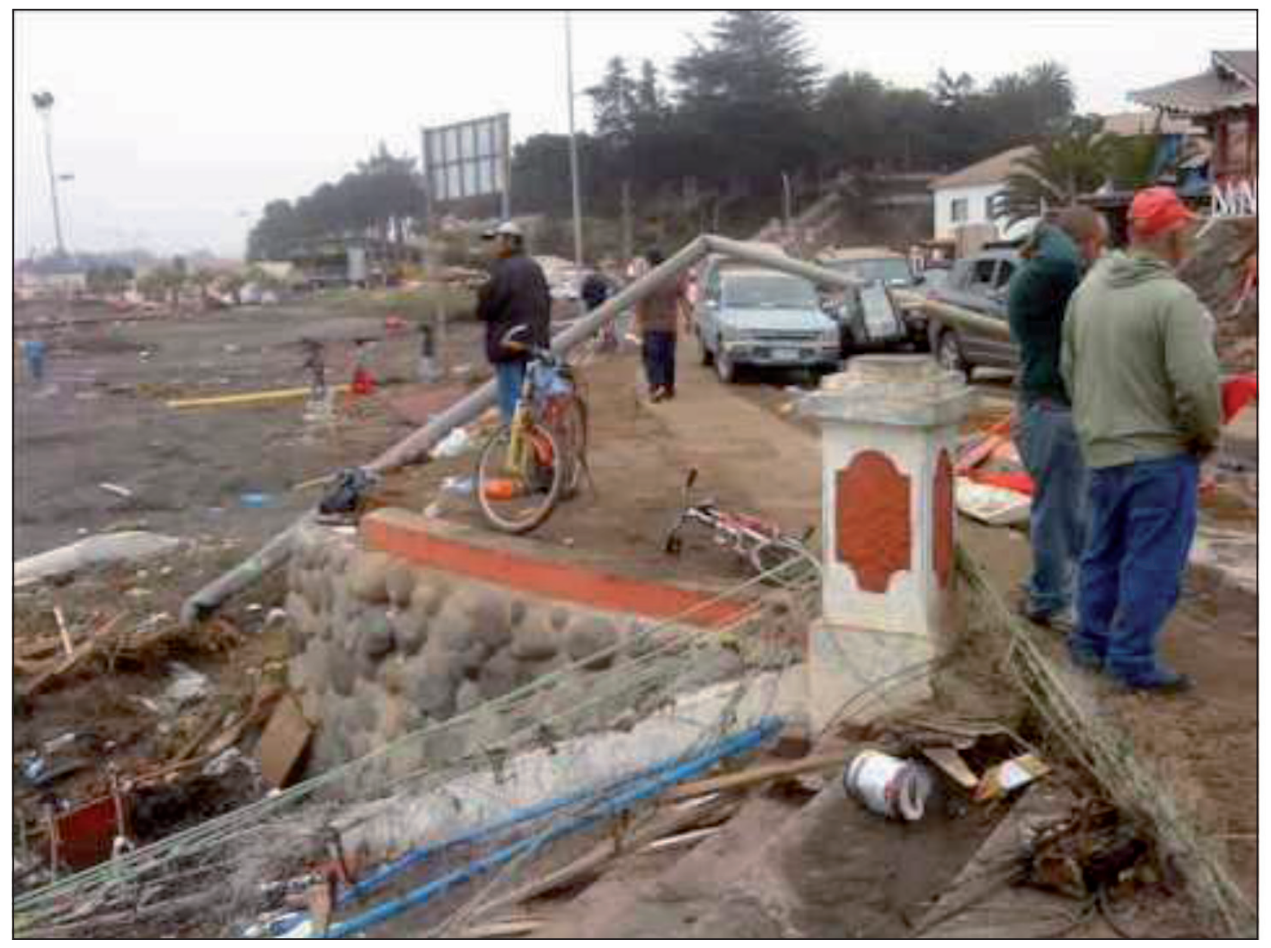

Pichilemu, O'Higgins Region. The effect of the 2010 Tsunami on low marine terrace, where there are tourist facilities (restaurants, playgrounds, accomodadtion), in the coastal avenue (Costanera); the effect on the shoreline was damage to the beach housing and tourist facilities which were located in the backshore area. Fondecyt project Fondecyt 1100223. María-Victoria Soto., mvsoto@uchilefau.cl, Departamento de Geografía, Universidad de Chile. 